\title{
Comparison of Ionospheric Slab Thickness over Jeju Island, Islamabad and Dourbes with IRI-2016, NeQuick 2 and data ingested NeQuick 2 during 2015
}

\author{
Hadiqa Khan ${ }^{1}$, Afsheen Ameer ${ }^{1}$, Muhammad Ayyaz Ameen ${ }^{2}$ \\ ${ }^{1}$ NED University of Engineering and Technology, Karachi, Pakistan \\ ${ }^{2}$ Pakistan Space and Upper Atmosphere Research Commission (SUPARCO), Karachi
}

E mail (hadiqakhan77777@gmail.com).

\section{Accepted: 20 February 2020}

\begin{abstract}
The study involves determination of the ionospheric slab thickness $(\tau)$ by using Global Satellite Navigation System (GNSS) total electron content (TEC) and ionosonde critical frequency of F2 layer $\left(\right.$ foF $\left._{2}\right)$ during a moderate solar activity year 2015 of cycle 24 (annual sunspot number, SSN $=81.7$ ) over Jeju Island (Geog. coord. $33.49^{\circ} \mathrm{N}, 126.59^{\circ} \mathrm{E}$ ), Islamabad $\left(33.75^{\circ} \mathrm{N}, 7.87^{\circ} \mathrm{E}\right)$ and Dourbes $\left(50.09^{\circ} \mathrm{N}, 4.59^{\circ} \mathrm{E}\right)$. Generally, the results showed $\tau$ peak values around presunrise hours with minimum values at post-sunset. Significant variations in $\tau$ were observed at all stations at a given time because of large latitudinal range. It was found that winter $\tau$ values are higher than other seasons. $\tau$ was compared with different models including, the International Reference lonosphere (IRI-2016) and electron density profiler NeQuick 2. It was deduced that NeQuick 2 gave better estimation of $\tau$ at all stations. During summer, IRI model estimation of $\tau$ are better for all the stations under study, whereas NeQuick 2 gave better approximation of the thickness during equinox and winter. The study also includes ionosonde $\mathrm{foF}_{2}$ driven NeQuick 2 model which showed better results as compared to NeQuick 2. It is suggested that ionosonde $f_{0} F_{2}$ and GNSS TEC may be incorporated in NeQuick 2 to obtain real ionospheric thickness at the stations under study.
\end{abstract}

\section{(c) 2020 BBSCS RN SWS. All rights reserved}

Keywords: Ionosphere, Slab Thickness, NeQuick 2, Ingested

\section{Introduction}

Ionosphere is a part of the Earth's upper atmosphere where ions and electrons are present in quantities sufficient to affect the propagation of radio waves (Rishbeth \& Garriott, 1969). The study of ionospheric dynamics through various means is a major component of space science. Because of varying altitudes and electron densities of the ionospheric regions, different techniques are capable of probing ionosphere (Cummer \& Steven, 1997). It is the presence of electrons and ions which effectively makes the ionosphere a medium of propagation of high frequency radio wave. In ionosphere most radiations from atoms and molecules originate in the visible spectrum and instruments have been developed that are capable of measuring such radiations from the upper atmosphere (Rees \& Fuller-Rowell, 1989). The atmospheric dynamics have great impact on Earth's ionosphere as it mostly coincides with the atmosphere. Solar electromagnetic radiations are primarily the reason to produce electron in the ionosphere through the process called photoionization and the integral number of electron gives total electron content (TEC).

Ionospheric slab thickness, $\tau$ is defined as the ratio of TEC to electron density at the peak of the $\mathrm{F} 2$ layer $(\mathrm{NmF} 2)$ (in electrons $/ \mathrm{m}^{3}$ ). Slab thickness is an important parameter that may be contemplated as the depth of a hypothetical ionosphere which has the same TEC as the actual ionosphere and its electron density is equal to the maximum electron density of ionosphere (Breed, et al., 1997) (Huang \& Yuan, 2015). Ionospheric slab thickness not only provides knowledge about topside and bottomside ionosphere but also elucidates structure of electron density with reference to height profile and is usefully employed in modelling the ionosphere such as the International Ionosphere Reference (IRI) (Bilitza D. , International reference ionosphere 2000, 2001). A study of this parameter at any location provides crucial information about the nature of the distribution of ionization at that location (Jayachandran, Krishnankutty, \& Gulyaeva, Climatology of ionospheric slab thickness, 2004). Strong correlation between slab thickness and plasma scale height is reported in Stankov \& Warnant, (2008) while Titheridge, (1973(a)) discovered relation of slab thickness with neutral temperature hence slab thickness by virtue of its relation to vertical plasma scale height, provides information on neutral and ion gas temperature (Stankov \& Warnant, 2008). Numerous studies have been reported on slab thickness over past few decades under different geophysical conditions e.g. (Bhonsle, Da Rosa, \& Garriott, 1965); (Titheridge, J. E., 1973(b)); (Huang \& Yuan, 2015). For low latitudes Bhuyan, (1986); (Jayachandran(1995); (Davies \& Liu, 1991) have investigated the behavior of this parameter and over mid latitude Bhonsle, Da Rosa, \& Garriott, (1965); Titheridge, J. E., (1973(b)); Mc Namara \& Smith, (1982) and Gulyaeva, (1997) have contributed to ionospheric literature. Many researchers have found out diurnal, seasonal, and solar activity variations of slab thickness that's shows considerable dependence of slab thickness on the location of the observation station such as (Suvannasang, Wichaipanich, Leelaruji, Ishii, \& Supnithi) and similar study has been carried out by Venkatesh, (2011) in Indian region to observe variations of ionospheric parameters including slab thickness where the variation of slab thickness also corresponds to the variation range carried out in this study. The study covers a wide latitudinal range which initially aimed to cover mainly stations in Pakistan i.e. Sonmiani and Islamabad. At Sonmiani an ionospheric TEC receiver was set up at Sonmiani in May-2014 in collaboration with China Research Institute of Radiowave Propagation (CRIRP) (Ameen M. A., et al., 2019(a)) and TYC-Ionosonde installed in September 2017 ( Ameen M. A., et al., 2019(b)) due to which data availability for 2015 was not possible and instead two other station were included in the study. Previously no work has been carried out on ionospheric slab thickness in Pakistan despite of numerous researches carried out in past decades around the world.

Subsequently, for better understanding of ionospheric slab thickness, this study includes two ionospheric models, i.e. International Reference Ionosphere (IRI 2016) and NeQuick 2. IRI is the international standard empirical model for the terrestrial ionosphere since the 1960s which describes monthly averages of the electron density, electron temperature, ion temperature and ion composition in the altitude range from $50 \mathrm{~km}$ to $1000 \mathrm{~km}$ (Bilitza, D.; Reinisch, B. W., 2008) . IRI is established by Committee on Space Research (COSPAR) and the International Union of Radio Sciences (URSI). It is a global empirical model based upon data extracted from the ground and space-based measurement of the 
ionospheric characteristics across different atmospheric conditions ( (Bilitza, et al., 2006); (Bilitza, D.; Reinisch, B. W., 2008) The endeavor was triggered by the need for an ionosphere model for the satellite/experiment design and satellite data analysis (COSPAR) and for radio propagation study (URSI) but has meanwhile found a much broader range of users with space weather concerns (Bilitza, et al., 2017). IRI model was used in many reports throughout the world for the comparison with GPS signal, for examples Rabiu et al. (2014), Asmare, Kassa, \&
Nigussie (2014), and Tariku (2015). NeQuick 2, developed at the International Center for Theoretical Physics in Trieste (ICTP) and at University of Graz, Austria, is a quick run 3-D electron density model from which TEC can be determined along any ground to satellite or satellite-satellite ray path by means of numerical integration Nava, Coisson, \& Radicella (2008) and Jakowski, Mayer, Hoque, \& Wilken (2011).

Table 1: Stations under research study

\begin{tabular}{|c|c|c|c|c|c|c|}
\hline \multirow{2}{*}{ Stations } & Country & \multicolumn{2}{|c|}{$\begin{array}{c}\text { Geographic } \\
\text { Coordinates }\end{array}$} & \multicolumn{2}{c|}{ Geomagnetic Coordinates } & Dip Angle \\
\hline Jeju Island & South Korea & $33.49^{\circ} \mathrm{N}$ & $126.53^{\circ} \mathrm{E}$ & $35.11^{\circ} \mathrm{N}$ & $83.71^{\circ} \mathrm{E}$ & $-7.55^{\circ}$ \\
\hline Islamabad & Pakistan & $33.68^{\circ} \mathrm{N}$ & $73.04^{\circ} \mathrm{E}$ & $25.51^{\circ} \mathrm{N}$ & $148.65^{\circ} \mathrm{E}$ & $2.70^{\circ}$ \\
\hline Dourbes & Belgium & $50.09^{\circ} \mathrm{N}$ & $4.59^{\circ} \mathrm{E}$ & $51.27^{\circ} \mathrm{N}$ & $88.93^{\circ} \mathrm{E}$ & $1.22^{\circ}$ \\
\hline
\end{tabular}
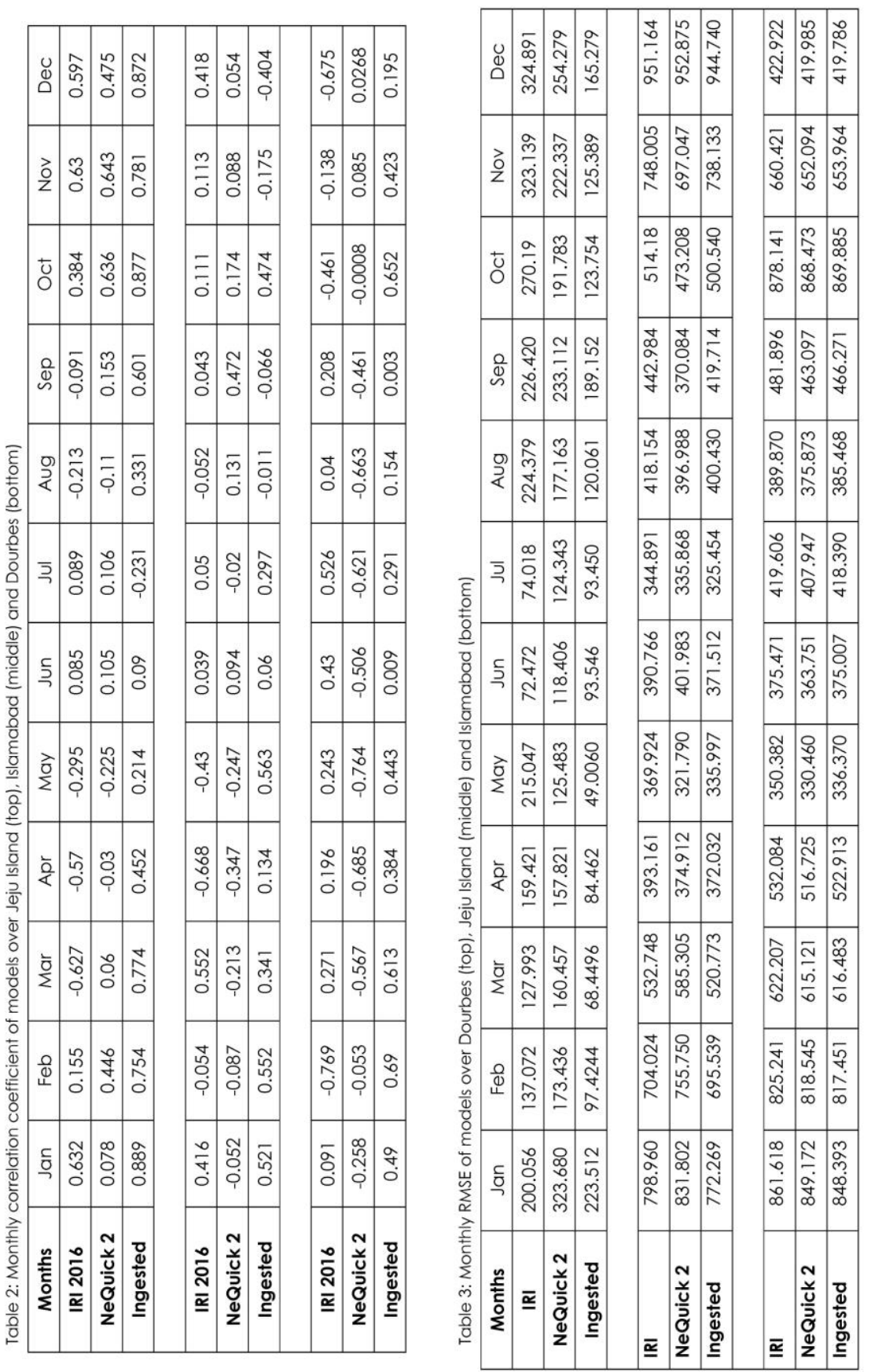


\section{Data analysis and methodology}

To study the variation in slab thickness $(\tau)$, the geographic and geomagnetic coordinates of the stations under study for solar moderate year 2015 are given in Table 1 .

The calculation of $\tau$ employed ionospheric parameters, i.e. total electron content (TEC) and maximum electron density of $F_{2}$ layer $\left(\mathrm{NmF}_{2}\right)$, governed by the following relation:

$$
\tau=\frac{T E C}{N m F_{2}}
$$

Computation of $\mathrm{NmF}_{2}$ is based on the given relation (Goodwin, Silby, Lynn, Breed, \& Essex, 1995), for this purpose critical frequency of $F_{2}$ layer $\left(f o F_{2}\right)$ data is fed into the following:

$$
\mathrm{NmF}_{2}=1.24 \times 10^{10} \times\left(\mathrm{foF}_{2}\right)^{2}
$$

Ground based GNSS receiver is used to obtain TEC over Islamabad which is manufactured by Septentrio Satellite Navigation, Belgium. The same model of the instrument is also being used at Dourbes. Likewise, ground based GNSS receiver for TEC is operated at Jeju Island, manufactured by Novatel, Calgary. The observed $\mathrm{foF}_{2}$ is obtained from ionograms of Digisonde DGS-256 at Islamabad and DPS-4D at Dourbes and Jeju Island (for details see http://www.digisonde.com/).

At Islamabad, TEC and $\mathrm{foF}_{2}$ were used for international quie days (IQDs). In this way the entire year is represented by 120 IQDs with 10 IQDs per month. The TEC and foF2 *were then obtained by medians per hour per month for the purpose. Data was processed to obtain hourlly monthly median values of both parameters $(\mathrm{LT}=\mathrm{UT}+05)$. Hourly median data for Jeju Island was received in UT $(\mathrm{LT}=\mathrm{UT}+09)$ upon requesting Korean Space Weather Center (KSWC). Royal Meteorological Institute (RMI) provided data of five minutes frequency for Dourbes in UT $(\mathrm{LT}=\mathrm{UT}+02)$ on request. Due to different format of text files, data harmonization was carried out to extract monthly hourly values of parameters as similar to Islamabad data.

For the comparative analysis IRI 2016 and NeQuick 2 were used toderivemodel estimations. Monthly hourly median values for TEC and $\mathrm{foF}_{2}$ were extracted from the models. Furthermore, for the purpose of model validation an exercise is performed by feeding ionosonde $\mathrm{foF}_{2}$ as input parameter into NeQuick 2 hence executing an iterative process to derive TEC from model corresponding to ionosonde $\mathrm{foF}_{2}$. To evaluate the precision of the models, the correlation coefficient (CC) and Root Mean Square Errors (RMSE) were calculated. The correlation coefficient is given by:

The CC values for the stations after comparison have been given in Table 2.

$$
C C=\frac{\sum_{i=1}^{N}\left(\tau_{\text {model }}-<\tau_{\text {model }}>\right)\left(\tau_{o b s}-<\tau_{o b s}>\right)}{\sqrt{\frac{\sum_{i=1}^{N}\left(\tau_{\text {model } e l}-<\tau_{\text {model }}>\right)^{2}}{N} \sqrt{\frac{\sum_{i=1}^{N}\left(\tau_{o b s}-<\tau_{o b s}>\right)^{2}}{N}}}}
$$

RMSE is calculated by the formula given below, have been represented in Table 3 :

$$
R M S E=\sqrt{\frac{\sum_{i=1}^{N}\left(\tau_{o b s}-\tau_{\text {model }}\right)^{2}}{N}}
$$

The behavior of $\tau$ is studied as monthly and seasonal variation. For monthly variation, peak and extreme values of $\tau$ (observed and model estimated) were analyzed. The overall trend of slab thickness during each month was examined and compared with that of the models. Monthly variation involved presentation of observed slab thickness for all stations as in Figures 1-3 where the top left panel represents January and bottom right subplot stands for December from right to left. Monthly model outputs of $\tau$ have been shown in Figures 4-6 with same distribution as for Figures $1 \div 3$.

Since all the stations lie in Northern hemisphere the effective seasonal distribution was grouped as, Winter (January, February,
November, December), Equinox (March, April, September, October) and Summer (May, June, July, August). The observed seasonal $\tau$ were compared with model estimated seasonal $\tau$. The comparisons have been shown in Figures 7-9 such that the top subplot represents winter, middle one shows summer values and the bottom panel stands for equinox in all figures.

In addition to the comparative study of $\tau$ with model estimations, an exercise was carried out for the purpose of model validation. The code of NeQuick model consist of a module called 'slQu'. For $f_{o F} F_{2}$ ingestion as a parameter the routine 'slQu.for' was used. This driver takes input from the user and calculates electron density profile generating TEC in an output file 'slQu.dat'. For default setting of the code, the subroutine of this module 'dat t SSN' is responsible for taking date, time, location and sunspot number as input while subroutine 'rays' is meant for calculating ray points and verify whether the ray end point cutting the sphere of earth or not. Based upon CCIR coefficient the $f_{o} F_{2}$ values are retrieved from the ASCII data file for each month. For given day of the month and time these $f_{o F_{2}}$ values called gamma function are read by the main program to generate TEC values.

Exercise involved feeding ionosonde $f_{o} F_{2}$ as input parameter into NeQuick 2 hence executing an iteration process to derive TEC from the model corresponding to ionosonde $f o F_{2}$. The $f o F_{2}$ values were read by the main program for given day of the month and time. Thus these $f o F_{2}$ values are called 'gamma function' which was bypassed in NeQuick model code by enabling user to provide critical frequency.

\section{Results and Discussion:}

\subsection{Monthly Variation of $\mathrm{T}$ :}

\subsubsection{Observed Results:}

At Jeju Island, the value of slab thickness for the complete 12 months ranges approximately from $500 \mathrm{~km}$ to $1800 \mathrm{~km}$. It can be seen from Figure 1 that the larger value of $\tau_{\mathrm{obs}}$ are depicted in month of December while least value of observed $\tau$ appears in October. It is curious to see discrepancy of $\tau$ as a purpose of day to day instability or monthly periodicity (Bhuyan, Tyagi, \& Tyagi, 1986). It can be seen that the maximum values are occurring at pre-sunrise hour where two factors accompanying these peaks are electric field and zonal neutral wind (Kenpankho, Supnithi, Tsugawa, \& Maruyama, 2011(b)).

At Islamabad, the value of slab thickness ranges approximately from $300 \mathrm{~km}$ to $1600 \mathrm{~km}$ approx. $\tau$ is significantly greater during January to March \& October to December, precisely at nighttime, refer to Figure 2.. Kakoti, Bhuyan, \& Hazarika (2017) reported a higher winter daytime TEC in in 2011, 2013 \& 2014 during solar cycle 24 . It is seen that the ratio is nearly equal in the solstices in 2010, (77 solar flux unit (sfu)) while in the high activity year 2014, (137 sfu) the ratio is higher between November to February thus giving rise to increased TEC. Observed $\tau$ followed same monthly trend, since equation 1.1 suggests direct relation of TEC and $\tau$, which is attributed to the $\mathrm{O} / N_{2}$ ratio. Therefore, it may be suggested that while during summer, the thermospheric $\mathrm{O} / \mathrm{N}_{2}$ ratio remains nearly unsteady, at the end of the year it increases with rise in solar activity and thus contributes to the observation due to winter anomaly in high activity years.

Over Dourbes (Figure 3), $\tau$ is maximum during January which is similar to the result carried out by Titheridge, (1973 (a)). Daytime variations are greater than nighttime variations in most of the months. During nighttime the cosmic radiations and high energy radiations through our own galaxy can produce significant fluctuation in the absence of sunlight which otherwise superimpose on these radiations in daytime. 


\subsubsection{Model Comparison of $\mathrm{T}$}

At Jeju Island, models underestimate the $\tau_{\text {obs }}$ throughout the year. If all the three models are compared, it is observed that in general nighttime values of ingested model are greater than rest of the models except for September to November. As is it visible from Figure $1 \tau_{\mathrm{obs}}$ is greater in nighttime which is as noticed by Jayachandran, Krishnankutty, \& Gulyaeva (2004) that the nighttime values are higher in middle latitudes. Whereas IRI 2016 and NeQuick 2 overestimate $\tau_{\mathrm{obs}}$ during daytime hence, ingested $\tau$ is in close proximity with $\tau_{\mathrm{obs}}$ as in Figure 4 .

Considering Figure 5, over Islamabad the model estimation trend shows resemblance with that of Jeju Island. It must be noted that during nighttime NeQuick 2 and ingested model show synchronous pattern for most of the months but during daytime IRI and NeQuick 2 give approximately same pattern whereas the trend estimated by ingested NeQuick 2 is followed by $\tau_{\text {obs }}$.

From Figure 1 it is observed that $\tau_{\text {obs }}$ give larger value in daytime while Figure 6 shows that NeQuick 2 gave contradict result. Similar trends were observed by Kenpankho, Watthanasangmechai, Supnithi, Tsugawa, \& Maruyama (2011) that during nighttime, the lowest slab thickness variation occurs at mid latitude. Contrary to NeQuick 2, uniformity in ingested model is noticed. The discrepancies between the models could be due to the fact that continuous data of Dourbes has been updated into the NeQuick 2 model.

Out of the three models used the best performance is depicted on the basis of least RMSE values which were found using Ingested model as expected because observed $f_{o} F_{2}$ values were ingested in NeQuick 2 model whereas IRI shows least efficient performance with highest RMSE values for all the stations refer to Table 3.

\subsection{Seasonal Variation:}

To examine the seasonal variation at Jeju Island, maximum and minimum $\tau_{\text {obs }}$ is observed during winter i.e. $1432 \mathrm{~km}$ and 479 $\mathrm{km}$ respectively (Figure 7). The results of seasonal trends have been observed that the nighttime values of $\tau$ are larger as compare to the daytime values in winter and equinox during solar minimum, except for summer where the turnaround appears to be true at low and mid-latitudes (Jayachandran, Krishnankutty, \& Gulyaeva, Climatology of ionospheric slab thickness, 2004). The decrement in $\tau$ value from nighttime to daytime is portrayed during winter, whereas during summer it shows increment from night to day (Davies \& Liu, 1991). This upgrade in slab thickness in winter in nighttime is created because of downward motion of $\mathrm{O}^{+} / \mathrm{H}^{+}$transition height. Least values of $\tau$ is found during summer at nighttime because lower value of TEC is produced due to alteration of composition of ionospheric components.

It is obvious from the Figure 8 at Islamabad that maximum $\tau_{\mathrm{obs}}$ is observed at 2000LT. The local minimum for foF2 is around 2000LT which may be caused by the strong eastward electric field and developing fountain effect (Balan \& Bailey, 1995). Predominantly least variation is spotted during summer months. Chuo, 2007 evinced that mostly, low values of TEC and NmF2 in summer as compared to other seasons are due to the atmospheric composition changes, commonly known as seasonal anomaly. High values of $\mathrm{NmF} 2$ and smaller slab thickness in equinox as compared to winter around midnight are caused by the convergent wind toward the equator. It is important to note that there is aberrant pre-sunrise peak $(931.1 \mathrm{~km})$ in slab thickness at 0400LT in summer. Electric field and zonal neutral wind may be the two major factors responsible for this pre-sunrise peak (Kenpankho, Watthanasangmechai, Supnithi, Tsugawa, \& Maruyama, 2011). As suggested by Yeh \& Flaherty, 1996 the slab thickness shows maximum value in summer and minimum value in winter, and hence the protonosphere may act as a reservoir, being filled up in daytime at the expense of summer hemisphere ionosphere and being emptied at night perhaps to both summer and winter hemisphere, but the current study contradicts this reason and shows maximum during winter. This behavior needs further investigation.

In Figure 9, at Dourbes it can be seen that the highest and lowest seasonal medians occur in winter. In summer season, the average values of $\tau$ are higher as compared to equinox and winter with steady variation pattern (Jin, Cho, \& Park, 2007). The reason behind this behavior is the alteration of NmF2 across the seasons. The electron density of F2 layer depends upon concentration of $\mathrm{N} 2$ and $\mathrm{O} 2$ that causes loss in its density and concentration of $\mathrm{O}$ that produces gain in its density. The ratio of $[\mathrm{O}] /[\mathrm{N} 2]$ is 2.3 times larger in winter than in summer. Consequently, the $\mathrm{NmF} 2$ is higher in winter than in summer as suggested by Cox \& Evans, 1970. The results of Dourbes exhibits that the average values of $\tau$ are higher in winter as compare to summer and equinox.

\section{Conclusion:}

In this study, the $\tau$ was observed to be increasing with time during midnight hours while during pre-noon hours a downward trend is perceived at Jeju Island and Islamabad whereas Dourbes depicts contradict results. The analysis of seasonal observation indicated higher value of $\tau$ during the winter solstice and lowest in the summer solstice at all stations. IRI 2016 produced higher RMSE than NeQuick 2 at all stations. The behavior of ingested model is relatively similar as NeQuick 2 but data driven model produced more efficient result than NeQuick 2 due to least RMSE values (Table 3) and higher correlation coefficient (CC) (Table 2). It may be concluded that if continuous $f_{o F_{2}}$ and TEC data is incorporated then it is possible that real ionospheric slab thickness would be mapped with better confidence at the stations under study.

\section{Acknowledgments}

The authors would like to express gratitude to the Korean Space Weather Center (KSWC) and Royal Meteorological Institute (RMI) for providing the data. Hadiqa Khan and Afsheen Ameer would like to acknowledge ICTP for providing the full support to present their work at ICTP Trieste Workshops SMR3292 \& SMR3328 in May \& October 2019, respectively. This work is an output of undergraduate final year research project for the award of degree by NEDUET, Karachi and was carried out at Pakistan Space Weather Centre (PSWC) with the support and supervision by SUPARCO. Valuable suggestions by the anonymous reviewers for the improvements of this manuscript are highly acknowledged also. 


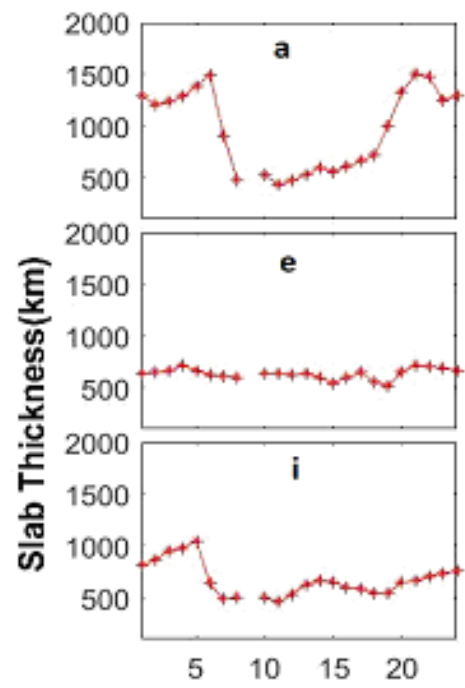

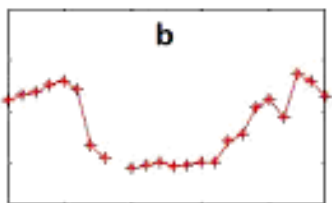
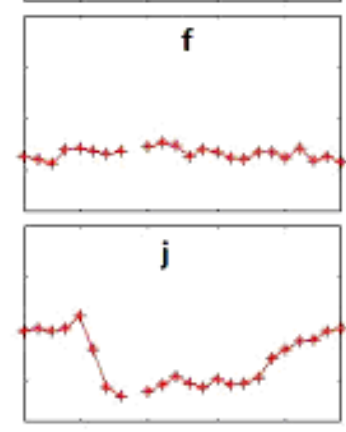

$\begin{array}{llll}5 & 10 & 15 & 20\end{array}$
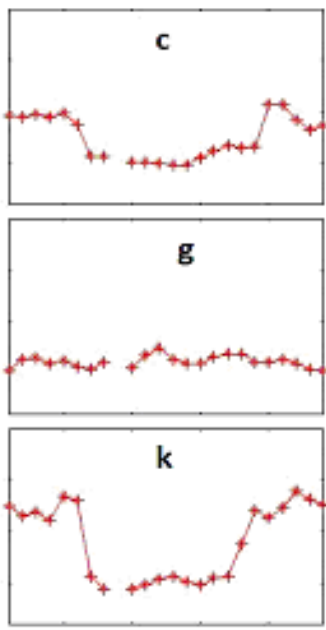

$\begin{array}{llll}5 & 10 & 15 & 20\end{array}$

LT(hrs)
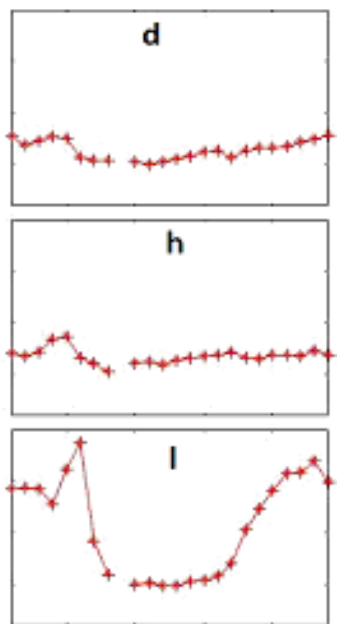

$\begin{array}{llll}5 & 10 & 15 & 20\end{array}$

Figure 1:Monthly Variation $\tau_{\text {obs }}$ over Jeju Island during 2015, Janaury(a)-December(l)
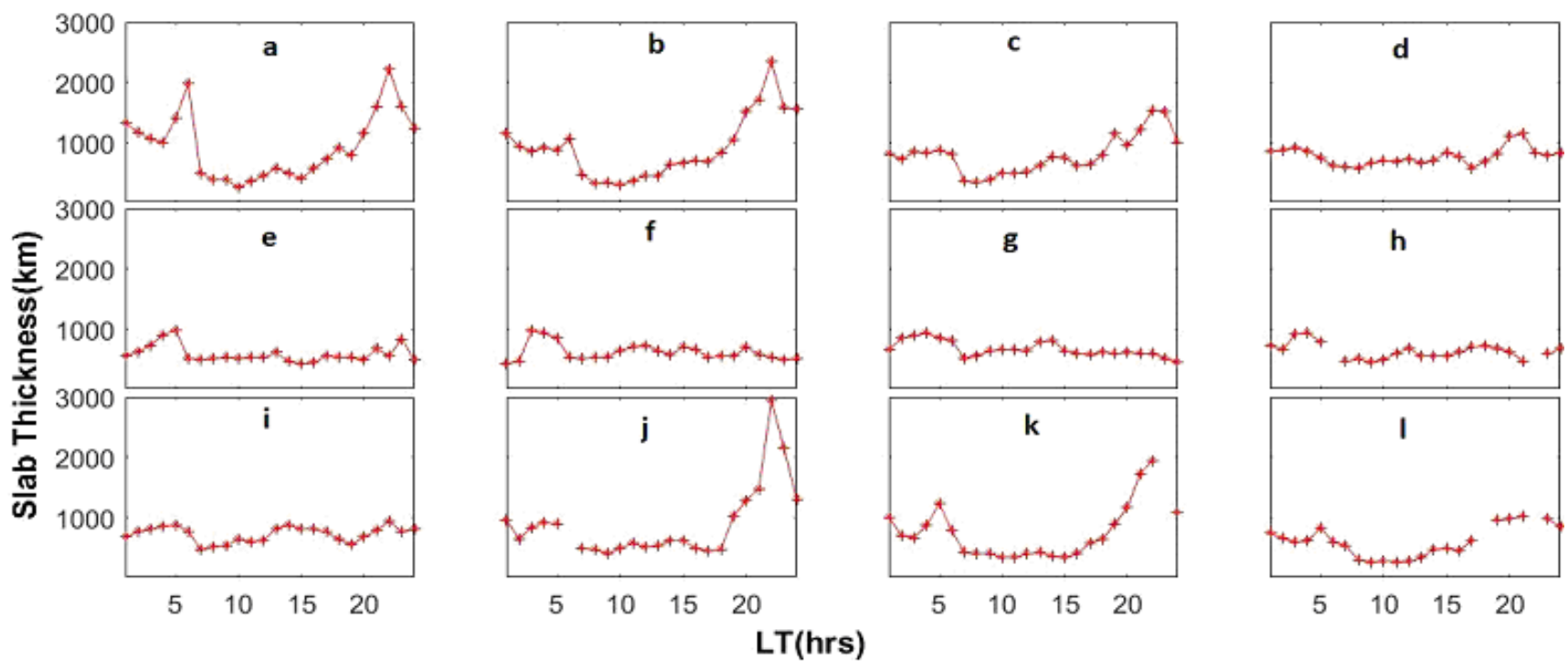

Figure 2: Monthly Variation $\tau_{\text {obs }}$ over Islamabad during 2015, Janaury(a)-December(l)
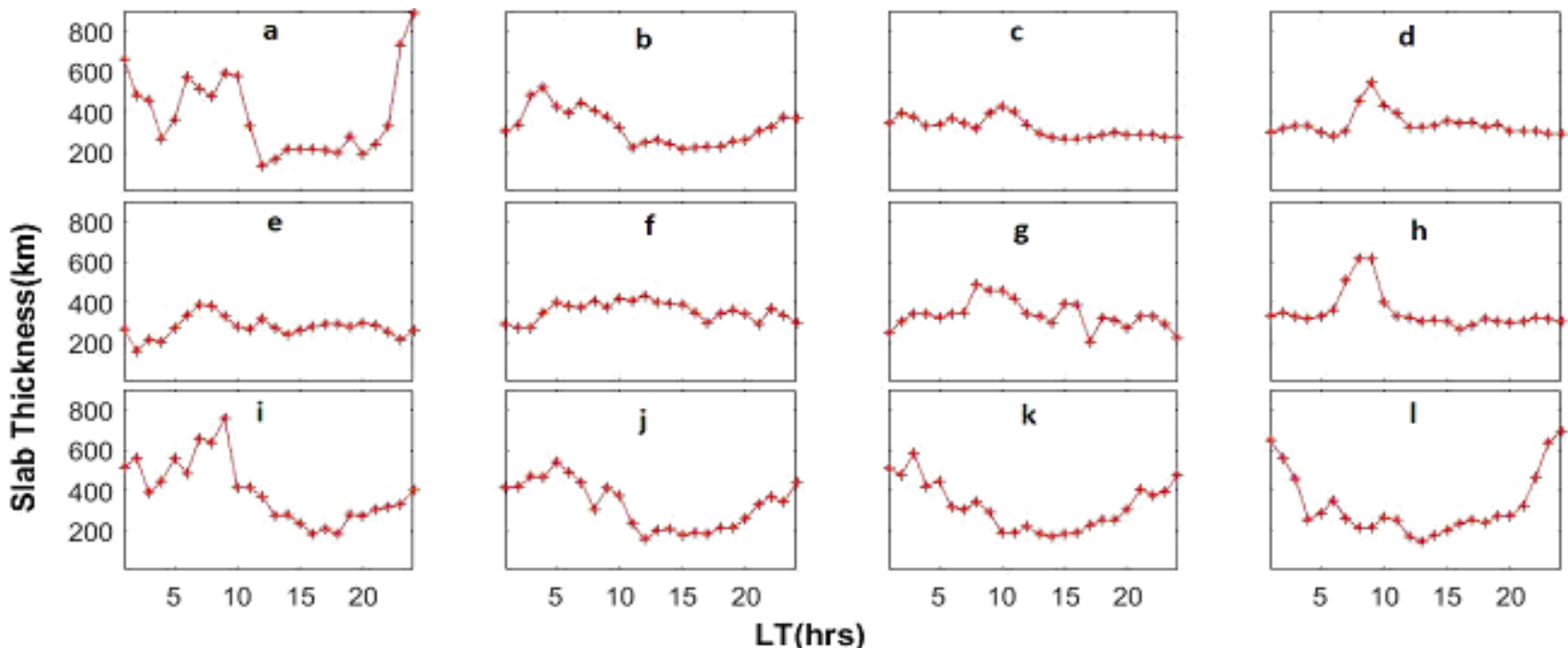

Figure 3: Monthly Variation $\tau_{\mathrm{obs}}$ over Dourbes during 2015, Janaury(a)-December(l) 

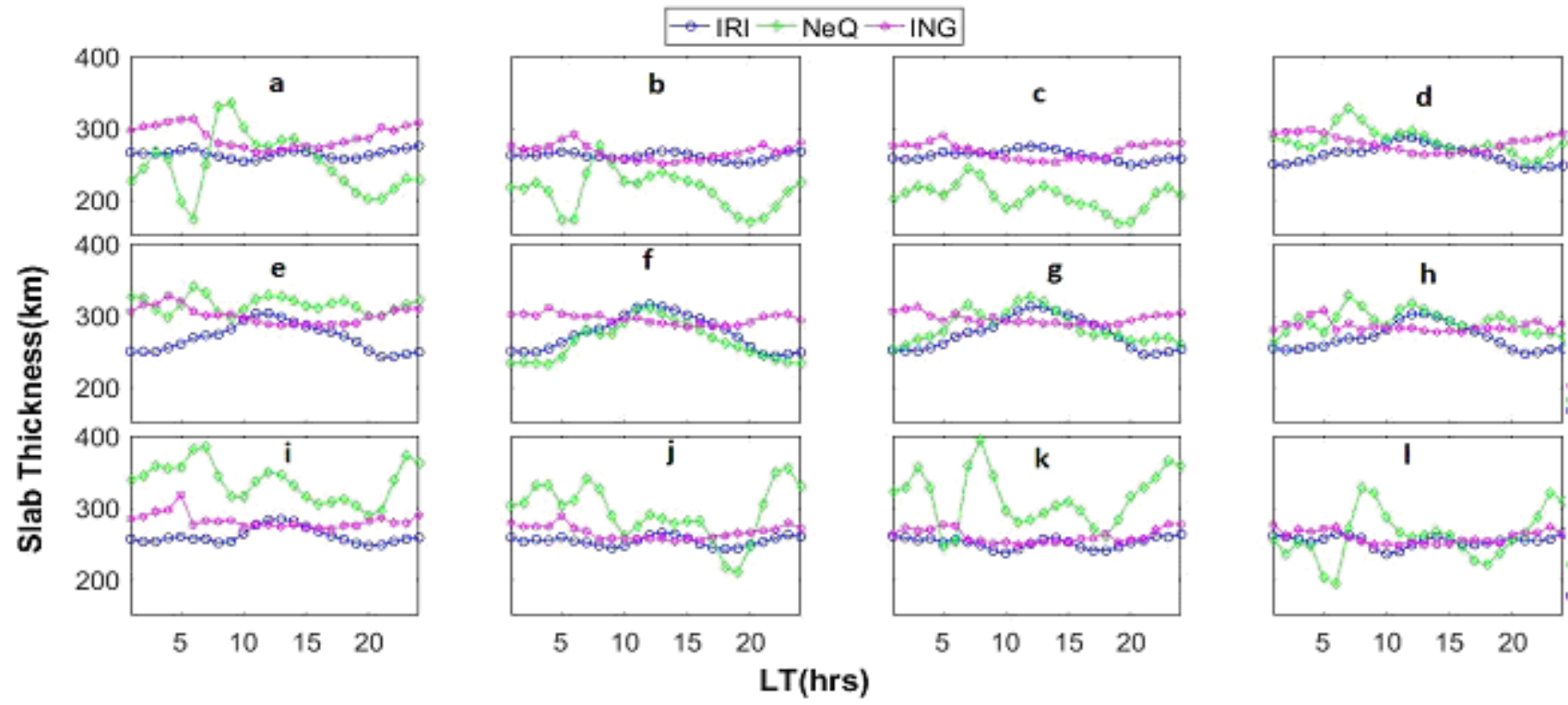

Figure 4: Comparison of model estimated $\tau$ over Jeju Island during 2015, Janaury(a)-December(l)
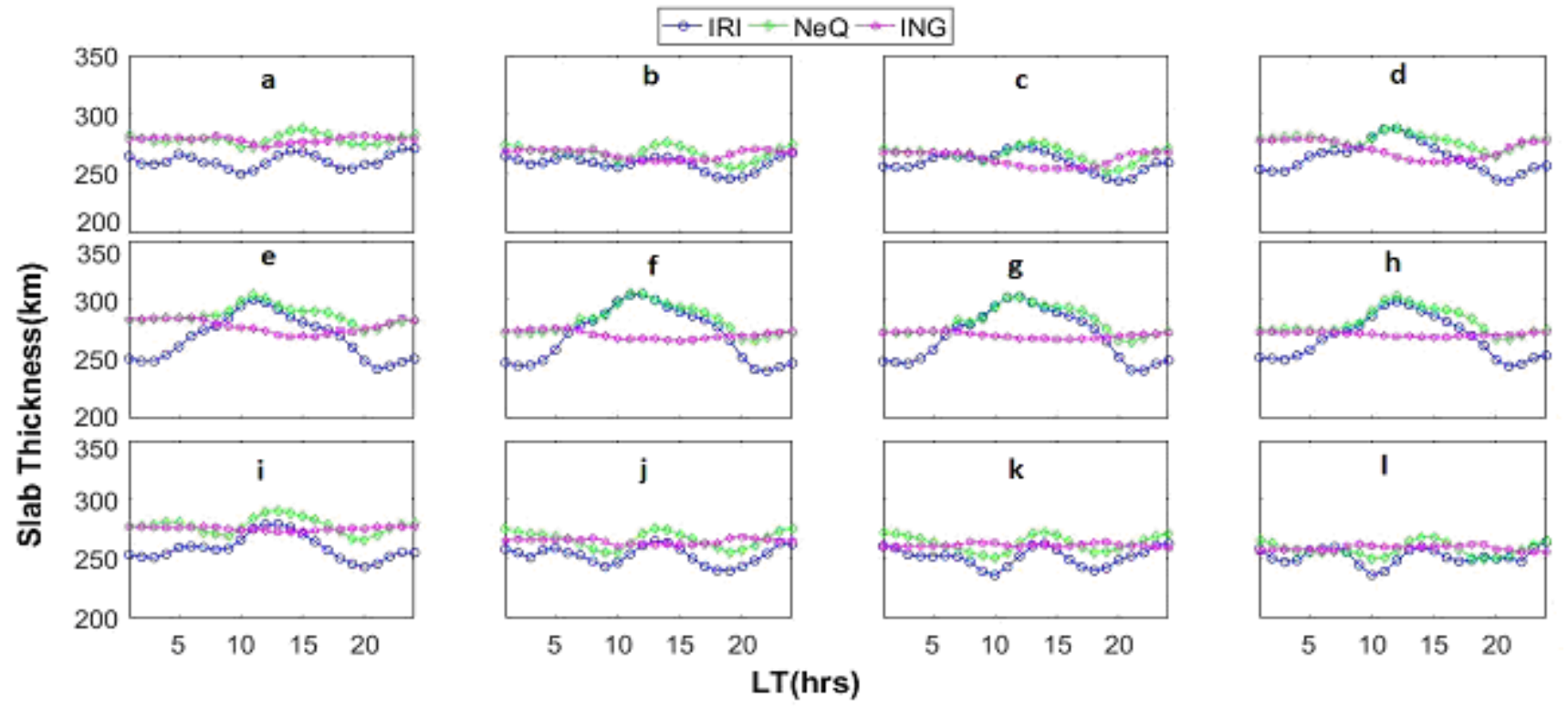

Figure 5: Comparison of model estimated $\tau$ over Islamabad during 2015, Janaury(a)-December(l)
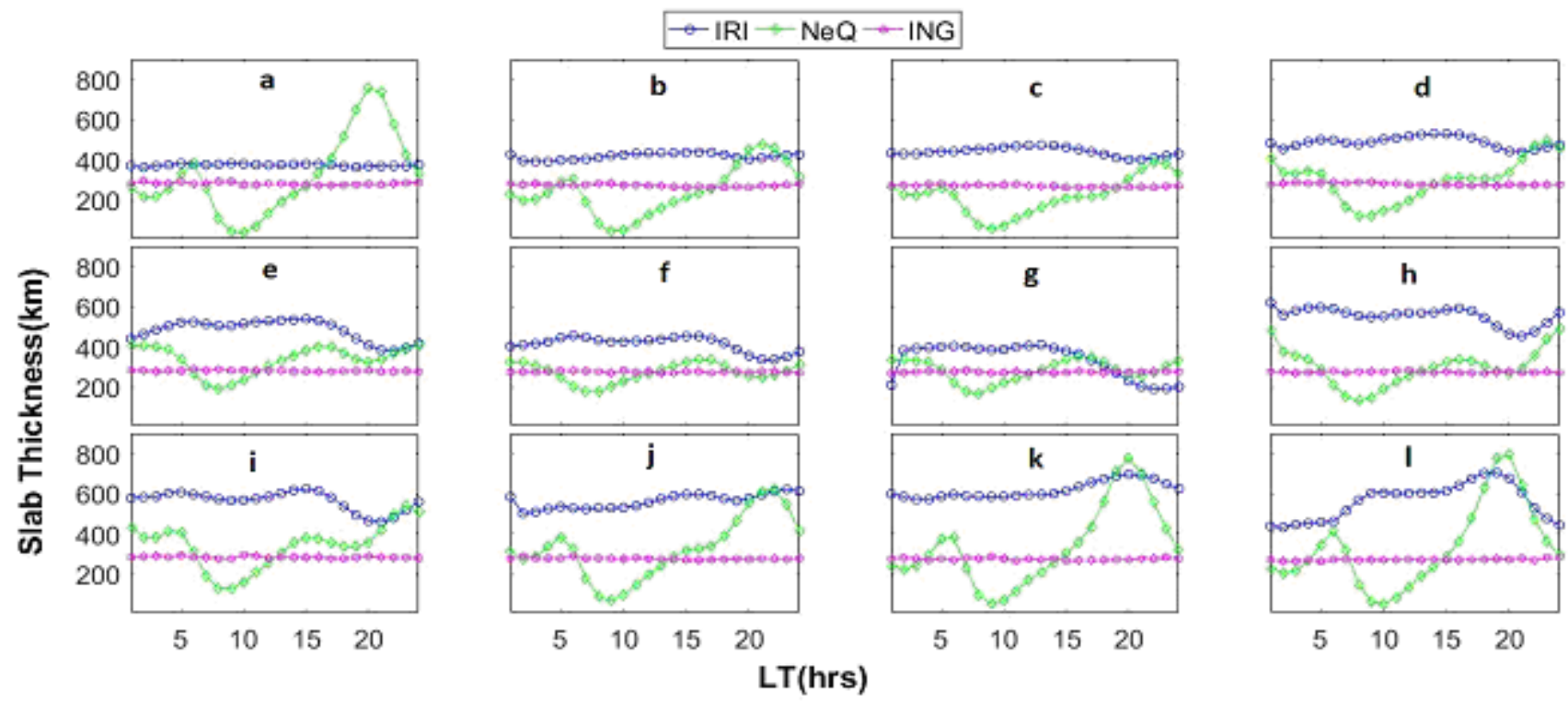

Figure 6: Comparison of model estimated t over Dourbes during 2015, Janaury(a)-December(l) 


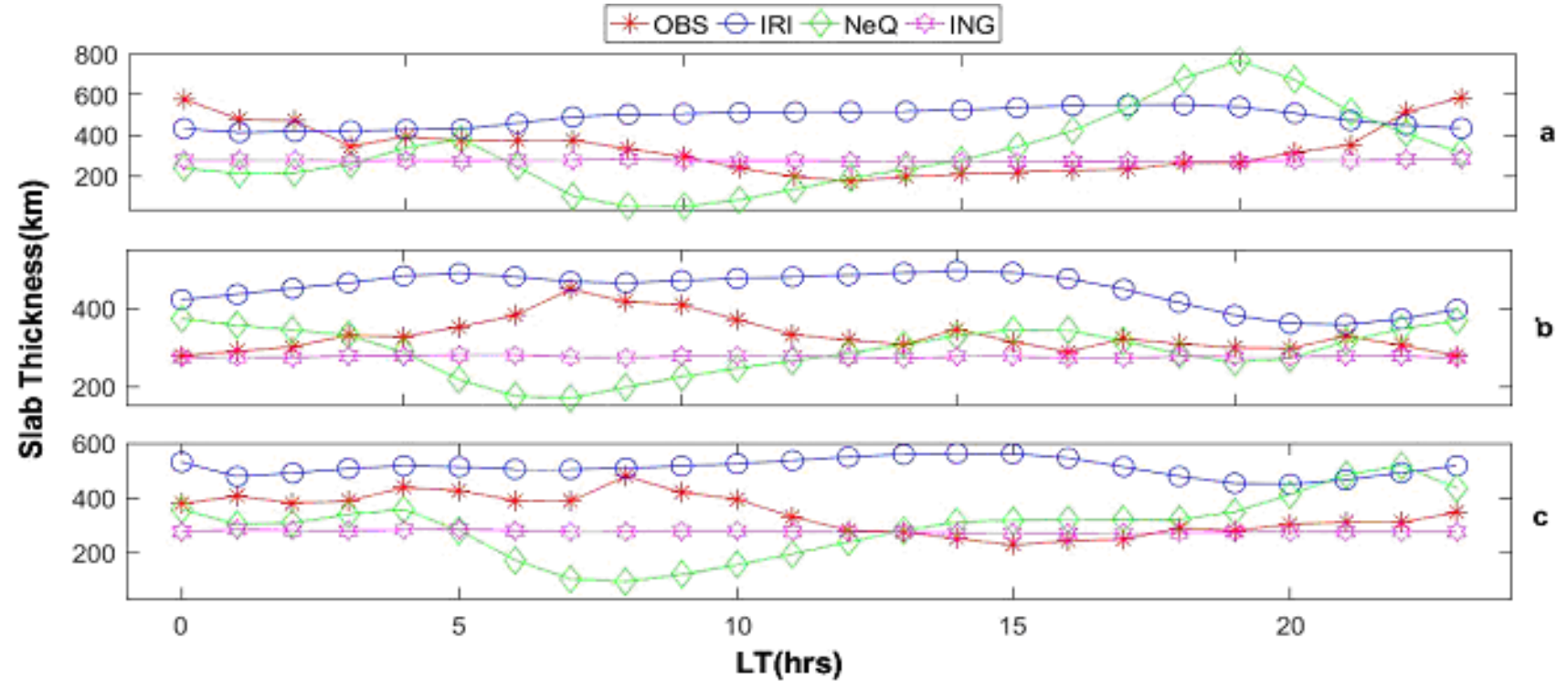

Figure 7: Comparison of $\tau_{\mathrm{obs}}$ with model estimated $\tau$ over Jeju Island during 2015, (a) winter, (b) summer, (c) equinox

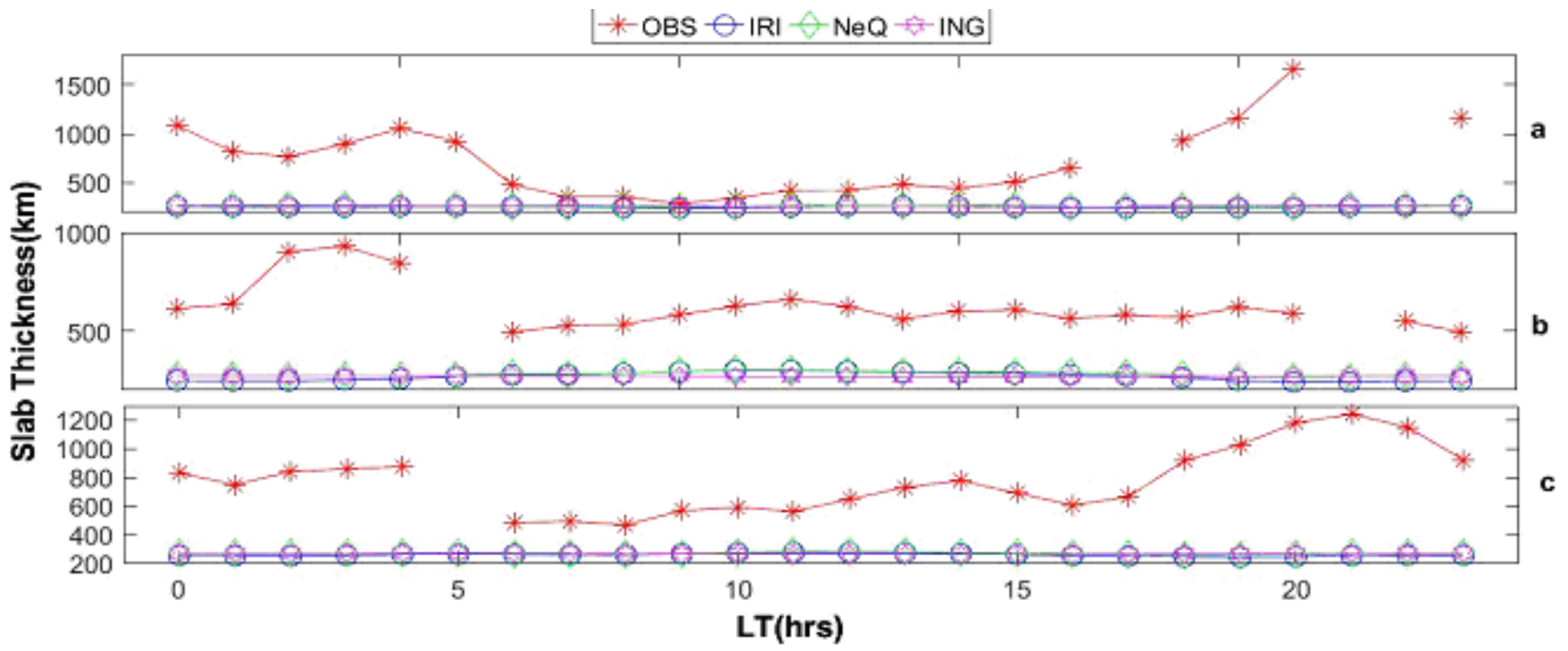

Figure 8: Comparison of $\tau_{\text {obs }}$ with model estimated $\tau$ over Islamabad during 2015, (a) winter, (b) summer, (c) equinox

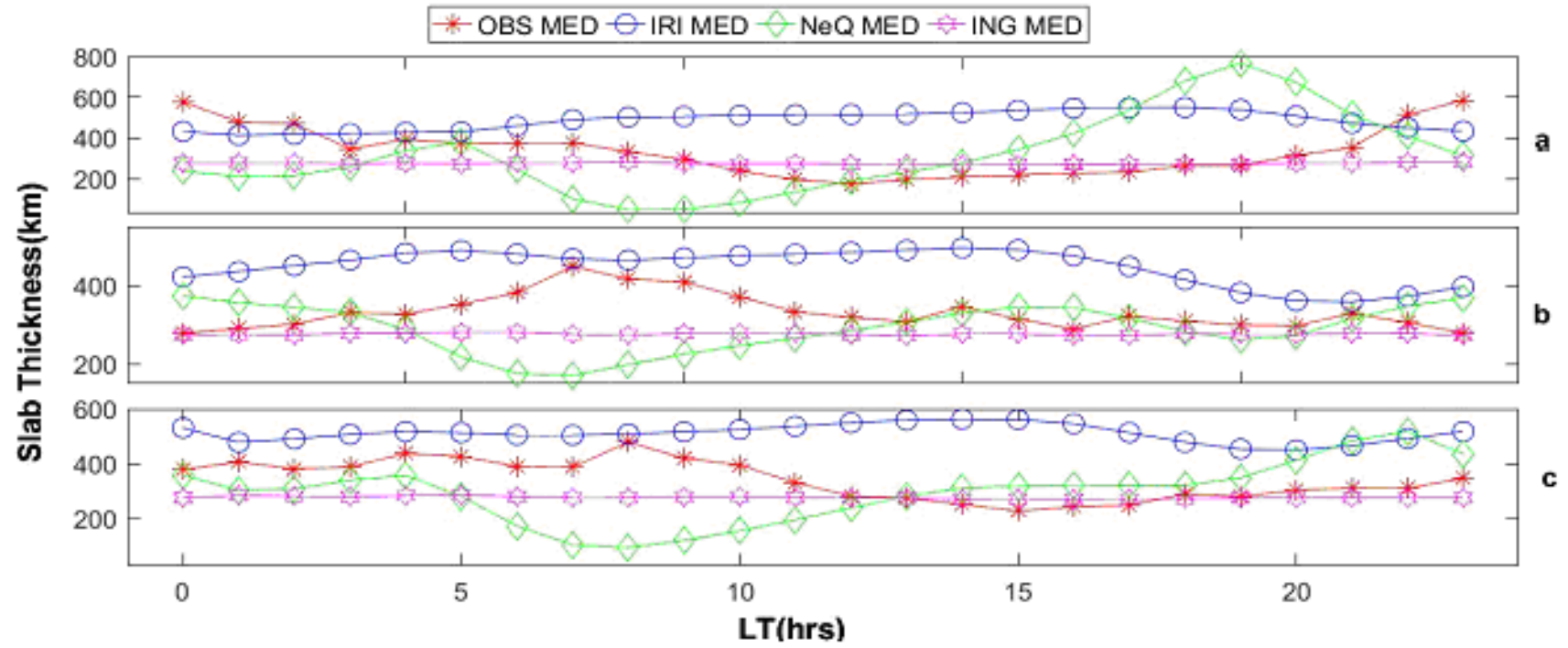

Figure 9: Comparison of $\tau_{\text {obs }}$ with model estimated $\tau$ over Dourbes during 2015, (a) winter, (b) summer, (c) equinox 


\section{References}

Ameen, M. A., Jabbar, M. A., Murtaza, G., Chishtie, F., Xu, T., Zhen, W., . . . Salman Ali, M. (2019(b)). Single station modelling and comparison with ionosonde foF2 over Karachi from 1983 to 2007,. Advances in Space Research, 64, 21042113.

Ameen, M. A., Jabbar, M., YU, X., Zhen, W., Murtaza, G., Chishtie, F., . . . Atiq, M. (2019(a)). Comparison of Ionospheric Total Electron Content (TEC) over Sonmiani (Pakistan) with NeQuick-2 and IRI-2012 during July 2014 June 2015. Advances in Space Research. 63. 10.1016/j.asr.2018.09.017.

Asmare, Y., Kassa, T., \& Nigussie, M. (2014). Validation of IRI-2012 TEC model over Ethopia during solar minimum (2009) and solar maximum (2013) phases. Adv. Space Res. 53, 1582 1594.

Balan, N., \& Bailey, G. J. (1995). Equatorial plasma fountain and its effects: Possibility of an additional layer. Journal of Geophysical Research: Space Physics, 100 (A11), 2142121432.

Bhonsle, R. V., Da Rosa, A. V., \& Garriott, O. K. (1965) Measurement of total electron content and equivalent slab thickness of the midlatitude ionosphere. Radio Science, 69, 929-939.

Bhuyan, P. K., Tyagi, T., \& Tyagi, T. R. (1986). Equivalent slab thickness of the ionosphere over $26^{\circ} \mathrm{N}$ through the ascending half of a solar cycle. 4, 131-136. 131-136.

Bilitza, D. (2001). International reference ionosphere 2000. Radio Sciience, 36, 261-275.

Bilitza, D., D., A., Shubin, V., Galkin, I., Reinisch, B., \& Huang, X. (2017). International Reference lonosphere 2016: From ionospheric climate to real-time weather predictions. Space Weather, 15, 418-429.

Bilitza, D., Reinisch, B. W., Radicella, S. M., Sergey, P., Gulyaeva, T., \& Triskova, L. (2006). Improvements of the Interntional Reference Ionosphere Model for the topside elecron density profile. Radio Sci. 41, RS5S14.

Bilitza, D.; Reinisch, B. W. (2008). International Reference lonosphere 2007: Improvements and New Parameters. Advances in Space Research. 42, 599-609.

Breed, A. M., Goodwin, G. L., Vadenberg, A.-M., Essex, E. A. Lynn, K. W., \& Silby, J. H. (1997). Ionospheric total electron content and slab thickness determined in Australia. Radio Science, Volume 32, Number 4, Pages 1635-1643.

Chuo, Y. J. (2007). The variation of ionospheric slab thickness over equatorial ionization area crest region. Journal of atmospheric and solar-terrestrial physics, 69 (8), 947-954.

Cox, L. P., \& Evans, J. V. (1970). Seasonal variation of the O/N2 ratio in the $\mathrm{F} 1$ region. Journal of Geophysical Research, 75 (31), 6271-6286.

Cummer, \& Steven, A. (1997). Lightening and ionospheric remote sensing using VLF/ELF Radio Atmospherics. Planetary and Space Science, 21 (10), 1775-1793.

Davies, K., \& Liu, X. M. (1991). Ionospheric slab thickness in middle and low latitudes. Radio Science, 26(4),, 997-1005.

Goodwin, G., Silby, J., Lynn, K., Breed, A., \& Essex, E. (1995). GPS satellite measurements: ionospheric slab thickness and total electron content. Journal of Atmospheric and Terrestrial Physics, 57(14), 1723--1732.

Gulyaeva, T. L. (1997). TEC residual slab thickness between bottomside and topside ionosphere. Acta. Geod. Geoph. Hung., 32, 355

Huang, Y.-N. (1983). Some result of ionospheric slab thickness observations at Lunping. Journal or Geophysical Research, 88, 5517-5522.

Huang, Z., \& Yuan, H. (2015). Climatology of the ionospheric slab thickness along the longitude of $120^{\circ} \mathrm{E}$ in China and its adjacent region during the solar minimum years of 2007 2009. Annales Geophysicae. 33, 1311-1319.

Jakowski, N., Mayer, C., Hoque, M. M., \& Wilken, V. (2011). Total electron content models and their use in ionosphere monitoring. Radio Science, 46 (6).
Jayachandran, B., Krishnankutty, T. N., \& Gulyaeva, T. L. (2004). Climatology of ionospheric slab thickness. Ann. Geophys., 22, 25-33.

Jayachandran, B., Nair, R. B., Balan, N., \& Rao, P. B. (1995). Short term variabilities of ionospheric electron content (IEC) and peak electron density (NP) during solar cycles 20 and 21 for a low latitude station. Journal of Atmospheric and Terrestrial Physics, vol 57, issue 13, 1599-1609.

Jin, S., Cho, J.-H., \& Park, J.-U. (2007). Ionospheric slab thickness and its seasonal variations observed by GPS. Journal of Atmospheric and Solar-Terrestrial Physics, 69 (15), 18641870

Kakoti, G., Bhuyan, P. K., \& Hazarika, R. (2017). Seasonal and solar cycle effects on TEC at $95 \mathrm{E}$ in the ascending half (2009-2014) of the subdued solar cycle 24: Consistent underestimation by IRI 2012. Advances in Space Research, 60 (2), 257-275.

Kenpankho, P., Supnithi, P., Tsugawa, T., \& Maruyama, T. (2011(b)). Variation of ionospheric slab thickness observations at Chumphon equatorial magnetic location. Earth, Planets and Space, Volume 63, Issue 4, 359-364.

Kenpankho, P., Watthanasangmechai, K., Supnithi, P., Tsugawa, T., \& Maruyama, T. (2011). Comparison of GPS TEC measurements with IRI TEC prediction at the equatorial latitude station, Chumphon, Thailand. Earth, planets and space, 63 (4), 365-370.

Mc Namara, L. F., \& Smith, D. H. (1982). TEC of the ionosphere at 310 S. Journal of Atmospheric and Terrestrial Physics, Vol 44, Issue 3, 227-239.

Nava, B., Coisson, P., \& Radicella, S. M. (2008). A new version of the NeQuick ionosphere electron density model. Journal of Atmospheric and Solar-Terrestrial Physics, 70 (15), 18561862.

Rees, D., \& Fuller-Rowell, T. (1989). The Response of the Thermosphere and lonosphere to Magnetospheric Forcing. Philosophical Transactions of the Royal Society of London. Series A, Mathematical and Physical Sciences, 328(1598), 139-171.

Rishbeth, H., \& Garriott, O. K. (1969). Introduction to lonospheric Physics. New York: Int. Geophys. Ser., Vol. 14. Academic Press.

Stankov, S., \& Warnant, R. (2008). Ionospheric slab thickness: analysis and monitoring applications.

Suvannasang, P., Wichaipanich, N., Leelaruji, N., Ishii, M., \& Supnithi, P. (n.d.). The Variation of Ionospheric Slab Thickness at Thailand Equatorial Latitude Station. The 23rd International Technical Conference on Circuits/Systems, Computers and Communications (ITC-CSCC 2008).

Tariku, Y. (2015). Comparison of GPS-TEC with IRI-2012 TEC over African equitoria and low latitude regions during the period of 201-2013. l. Adv. Space Res. 56, 1677-1685.

Titheridge, J. E. (1973 (a)). The electron content of the southern mid-latitude ionosphere, 1965-1971. Journal of Atmospheric and Terrestrial Physics, 35 (5), 981-1001.

Titheridge, J. E. (1973(b)). The slab thickness of the mid-latitude ionosphere. Planetary and Space Science, 1775-1793.

Venkatesh, D., Rao, P., Prasad, D., Niranjan, K., \& Saranya, D. (2011). Study of TEC, slab-thickness and neutral temperature of the thermosphere in the Indian low latitude sector. Annales Geophysicae, 29, 1635-1645.

Yeh, K. C., \& Flaherty, B. J. (1996). Ionospheric electron content at temperate latitudes during the declining phase of the sunspot cycle. Journal of Geophysical Research, 71 (19), 4557- 4570. 